\title{
Active citizenship in the governance of anti-social behaviour in the UK: exploring the non-reporting of incidents
}

\author{
Rionach Casey and John Flint* \\ Sheffield Hallam University
}

\begin{abstract}
Promoting active citizenship in order to enhance the efficacy of formal and informal social control within local neighbourhoods is a key component of anti-social behaviour policy in the UK. Calls for citizens to 'take a stand' against anti-social behaviour characterises the emerging 'Respect' agenda alongside an increasing presence of 'official' authority figures, including additional police officers and wardens, in local communities. Reporting incidents of anti-social behaviour to local agencies is a key mechanism of active citizenship within local community safety interventions. However, this article highlights the scale of the non-reporting of anti-social behaviour in the UK and uses findings from two recent research studies in Scotland to identify nine explanatory factors for non-reporting. The article argues that the problem of nonreporting illustrates the ambiguity of policy conceptualisations of the relative roles of state and citizen and formal and informal social control processes within anti-social behaviour strategies.
\end{abstract}

Keywords: anti-social behaviour, active citizenship, formal and informal social control.

\section{Introduction}

"We [the government] believe it is time for the community to take a stand."

(Home Office, 2003: 13)

The Home Office's 2003 White Paper, Respect and Responsibility- Taking a Stand against Anti-social Behaviour, articulated key strands in contemporary governance rationales underpinning attempts to tackle anti-social behaviour in the UK within a developmental 'Respect' agenda focusing upon the moral values and norms of conduct within local communities. This agenda explicitly requires citizens to assume further responsibility for the nature of social interaction within their neighbourhoods and 
p. 70. Active Citizenship in the Governance of Anti-social Behaviour in the UK: Exploring the Non-Reporting of Incidents

exhorts individuals to engage in acts of citizenship in partnership with official enforcement agencies in order to address anti-social behaviour. This approach is epitomised in the concept of citizens 'taking a stand', which both suggests the limitations of formal social control enacted through state intervention and implies the inadequacy of existent levels forms of informal social control within neighbourhoods experiencing anti-social behaviour.

This article describes the rationales underpinning the attempts to increase the empowerment and responsibilities of local communities and to foster acts of citizenship in the governance of anti-social behaviour, linked to achieving a synergy between formal and informal mechanisms of social control (Innes and Jones, 2006; Flint, 2006). The article identifies the non- reporting of incidents of anti-social behaviour to official agencies as being illustrative of the problematic interface between formal and informal social control and the competing forms of authority and social norms operating within communities (Stenson, 2005). National- level survey evidence is used to quantify the scale of non-reporting in the UK and qualitative data from two recent research studies in Scotland is explored to identify the causal factors behind the reluctance of residents to engage with official agencies through the reporting of neighbourhood problems. The article concludes by arguing that the nexus between formal and informal social control is ambiguous and that a more nuanced consideration of the balance of roles and responsibilities between actors and the mechanisms for empowering residents is required within policy rationales.

\section{'Taking a stand' and the problem of non-reporting}

Two major Home Office policy papers have sought to articulate a reconfigured relationship between local communities and state agencies in tackling crime and antisocial behaviour (Home Office, 2003; 2004). Their titles: Respect and ResponsibilityTaking a Stand against Anti-social Behaviour and Building Communities, Beating Crime identify key government objectives of: (re)building 'respect' within society; fostering responsibility amongst 'active' citizens; utilising community processes to enhance the informal social control of anti-social behaviour; and facilitating the greater engagement of residents in the processes of formal social control within a 'wider policing family' (Home Office, 2004: 85).

This focus on responsibility and community processes is embedded within wider New Labour social and urban policy rationales emphasising individual duty and autonomy, communitarianism and a neighbourhood level-focus on the social and cultural as well as economic dynamics of exclusion. In turn, these rationales build on the promotion of active citizenship by the Conservative governments during the 1990s which realigned the predominant consumer-state-society relationship conceptualised by the Thatcher administrations of the 1980s and sought to enhance the role of individual citizens and the voluntary and community sectors within a 'rolling back' of the duties and functions of the state. This contemporary framing of the responsibilities of citizenship also has longer-term historical precedents including the focus upon the conduct of poorer households in the nascent urban policy and philanthropic housing movements of the late 19th-century and the conceptualisation throughout the 20th century of the welfare state as a mechanism for changing behaviour as much as for providing material assistance (see Flint, 2006 for a fuller discussion).

The Home Office (2003: 12) argued that: 'As a community we have a responsibility to speak out against the minority who cause misery and distress', whilst the Respect Action Plan stated that: 'Respect cannot be achieved by Government alone and ultimately every citizen has a responsibility ... to support the community [in behaving in 
p. 71. Active Citizenship in the Governance of Anti-social Behaviour in the UK: Exploring the Non-Reporting of Incidents

a respectful way]' (Respect Task Force, 2006: 3). Similarly, the devolved Scottish Executive (2003: 2-7) believed that: "communities have a responsibility for tackling anti-social behaviour' and 'must be involved in the solutions'. The governmentsponsored Taking A Stand Awards (in England and Wales) and Standing Up to Antisocial Behaviour Awards (in Scotland) epitomise this governmental exhortation towards citizens to actively engage in tackling anti-social behaviour, supported by initiatives such 'Its Your Call', the non-emergency 101 number and similar local schemes which provide new telephone hotlines for the reporting of anti-social behaviour (see Flint, 2006).

However previous research has identified problems and ambiguities within governmental attempts to facilitate the reporting of anti-social behaviour and has consistently found relatively low levels of reporting (Upson, 2006; Corbett et al., 2005; McVie et al., 2003). A range of national survey evidence has identified the scale of the non-reporting of anti-social behaviour to official enforcement agencies. For example, the 2003/2004 Scottish Household Survey revealed that almost half (48-percent) of respondents experiencing a neighbourhood problem or incident did not report it to either the Police or Local Authority. Table 1 highlights the consistently high levels of the non-reporting of anti-social behaviour in national surveys. Although there is some variation depending on the type of anti-social behaviour, in most cases a majority of respondents did not report an incident of anti-social behaviour that they directly experienced, and three quarters of respondents had not reported drugs-related antisocial behaviour. There is also little evidence to indicate that these levels of reporting have increased since the early 1990s (i.e. in the period since the current focus upon active citizenship and community governance emerged in UK crime and social policy discourse). Unfortunately, data is not available that would enable a comparative analysis of the levels of reporting in earlier historical periods.

Table 1: Non-Reporting of Anti-social Behaviour Incidents

\begin{tabular}{|c|c|c|c|}
\hline \multirow[t]{2}{*}{ Survey } & \multicolumn{3}{|c|}{$\begin{array}{l}\text { Residents not reporting an incident of } \\
\text { anti-social behaviour (\%) }\end{array}$} \\
\hline & Vandalism & $\begin{array}{l}\text { Noisy } \\
\text { neighbours }\end{array}$ & Drugs \\
\hline British Crime Survey 2004/05 & 73 & 39 & 73 \\
\hline $\begin{array}{l}\text { Scottish Executive Study Household } \\
\text { Survey } 2006\end{array}$ & 59 & 48 & 82 \\
\hline Scottish Crime Survey 2003 & 57 (a) & - & - \\
\hline Scottish Household Survey 2005 & 54 & 63 & 75 \\
\hline
\end{tabular}

Note: (a) This figure only includes reports to the police

Previous studies have also identified that competing social regimes of authority, expectations and cultural norms, combined with a fragile interface between citizens and official enforcement agencies, reduce the efficacy of crime and anti-social behaviour interventions in the worst-affected neighbourhoods (Atkinson and Flint, 2004; Stenson, 2005). The governance of anti-social behaviour in the UK is also characterised by the dual and often ambiguous processes of ceding powers and responsibilities to residents whilst simultaneously increasing the presence of state authority in neighbourhoods through the use of additional policing, wardens, professional witnesses, CCTV, Anti-social Behaviour Orders and Dispersal Orders (Flint, 2006). Whilst these two approaches are conceptualised as being mutually reinforcing 
p. 72. Active Citizenship in the Governance of Anti-social Behaviour in the UK: Exploring the Non-Reporting of Incidents

and generating powerful synergies in the determining and enforcement of required behaviour in local communities, they have also created tensions between the respective roles and responsibilities of state and citizen and the relationships between formal and informal mechanisms of social control. This article now turns to exploring how these issues play out in the non-reporting of anti-social behaviour within local communities, based on findings from two recent research studies in Scotland ${ }^{1}$

\section{The causal factors of non-reporting}

Our research identified nine explanatory factors for the non-reporting of anti-social behaviour incidents to official agencies.

\section{Residents not defining the incident as anti-social behaviour}

Some residents did not conceptualise certain forms of conduct as constituting antisocial behaviour. For example, an important finding from the 2004/05 British Crime Survey was that, of those respondents experiencing young people hanging around in their neighbourhood, a majority did not consider this to be a problem (Upson, 2006). Our studies found evidence that many residents did not always regard loud music or young people congregating as being problematic. This indicated a degree of tolerance within local communities that did not map onto strategies aimed at encouraging the reporting of each and every incident to local agencies.

\section{Incidents being too trivial}

Many residents in our research did not report an incident of anti-social behaviour as they regarded it as being trivial. This mirrors the findings of the British Crime Survey that between a quarter and a half of respondents cited the trivial nature of the behaviour as the explanation for them not reporting an incident (Upson, 2006). However, this explanation needs to be explored further. In one interpretation, residents viewed some incidents as "a one-off" or stated that it did not adversely affect them. Many residents also regarded the conduct of young people as 'kids just being kids", ' or reflected that "we were exactly the same at their age." However, there was also a process of normalising more serious forms of anti-social behaviour in which it became conceived as a part of everyday life that was not unusual in residents' neighbourhoods, and indeed was regarded by residents as being common in most other neighbourhoods. As one resident described:

"There is vandalism all the time and disruption from people running through the gardens ... otherwise it is a nice place to live."

These perceptions indicated a degree of stoicism amongst residents. However, they were also symptomatic of a level of tolerance towards anti-social behaviour that many agency officers perceived as not being present in more affluent neighbourhoods. It is important that such tolerance is not misinterpreted as condoning or 'turning a blind eye to' anti-social behaviour. Rather it is a manifestation of a sustained history of higher levels of anti-social behaviour within particular neighbourhoods whereby residents view

\footnotetext{
${ }^{1}$ The first study was an evaluation of anti-social behaviour policy and practice for the Glasgow Housing Association and the second study was a Scottish Executive-funded evaluation of the impact of local anti-social behaviour strategies at the neighbourhood level. Both studies were conducted between 2006 and 2007. For the full research reports and methodologies, see Flint et al. 2007a and Flint et al., 2007b.
} 
p. 73. Active Citizenship in the Governance of Anti-social Behaviour in the UK: Exploring the Non-Reporting of Incidents

even relatively serious anti-social behaviour as a fact of life in the context of no tradition of effective intervention by agencies or by residents themselves.

The fact that incidents of anti-social behaviour may not be reported to the authorities because residents do not define them as anti-social or regard them as trivial raises an important issue about the extent to which current policy facilitates a genuine internalisation of responsibility amongst citizens (King, 2006). Such a process would enable the agency, reflexivity and discretion of residents in determining in what circumstances behaviour is unacceptable and to decide whether a complaint to the authorities is the appropriate response. However the 'bounded autonomy' (Etzioni, 1995) within which citizens operate is rather narrowly interpreted within a current policy discourse that emphasises the need for citizens to report all forms of anti-social behaviour which is defined in a broad, if ambiguous, categorisation. In essence, citizens are encouraged to take responsibility through reporting anti-social behaviour to agencies, but are not empowered or entrusted with the responsibility to decide when they should engage in such acts of citizenship.

\section{Non-awareness of who to report incidents to}

One in ten respondents in the 2004/05 British Crime Survey did not report an incident due to a lack of awareness of who to report to (Upson, 2006). Our research suggests that this lack of awareness amongst residents may be more widespread than this figure indicates. There were different elements to this general lack of awareness. At a basic level, some residents were unaware of what agencies and services were actually operating in their neighbourhood, despite considerable publicity activity by these agencies. However, even those residents who had knowledge of the police, community wardens or local authority anti-social behaviour teams were often unsure about which types of anti-social behaviour should be reported to which agency and what particular responsibilities each agency had. There was therefore a lack of clarity regarding the specific role of individual agencies, and how they were connected to one another in responding to anti-social behaviour incidents. Residents were often not aware of specific measures being deployed in their neighbourhoods, such as Anti-social Behaviour Orders, or what role they were expected to play in 'policing' these measures. There was also a feeling of uncertainty amongst many residents about what constituted an 'appropriate' complaint.

\section{A lack of confidence in agencies}

Our studies found that a lack of confidence amongst residents about the willingness and capacity of the police and other agencies to tackle serious anti-social behaviour was a significant factor in the non-reporting of incidents. This again reflects findings from the 2004/05 British Crime Survey that many residents regard reporting an incident as 'a waste of time' (Upson, 2006). Residents' lack of confidence played out at a number of levels. Many residents perceived the police and other agencies to have a dismissive attitude towards complaints of anti-social behaviour, including serious criminality (the 2004/05 British Crime Survey found that 29 per cent of respondents believed that official agencies would not be interested in a complaint about drug use or dealing (Upson, 2006). Several of the residents that we interviewed reported being given 'excuses', 'platitudes' and the 'brush off' in place of appropriate action when attempting to report an incident. However, in some cases residents were less directly critical of local agencies including the police. Instead, they believed that the wider criminal justice system meant that 'it was not worthwhile' reporting incidents. One resident's view that: "There's only so much the police can do. They're hands are tied", 
p. 74. Active Citizenship in the Governance of Anti-social Behaviour in the UK: Exploring the Non-Reporting of Incidents

articulated a common belief amongst our research participants. This was combined by a widely-held perception that action against perpetrators was ineffectual:

"People who cause the trouble have nothing to fear....because reprimands don't work. They have no respect for the police."

"A lot of warning letters don't frighten the hard cases. They flare up again after a while."

A self-perpetuating cycle was set in motion whereby an initial lack of confidence in agencies or the measures available to them was borne out by experience, which reinforced the perceived futility of making a complaint. Subsequently, this contributed to a lack of evidence required by local agencies to take action, sustaining residents' interpretations of a lack of effective interventions.

\section{A. fear that reporting the incident will make things worse}

Our research found that residents were required to negotiate their fears and to balance their desire to report an incident with the likely consequences of this action on the nature of their relationship and social interface with the alleged perpetrator. The complexity of these 'rational choice' and cost-benefit factors in decision-making are not captured in the simplistic calls for residents to 'take a stand' or notions of a moral ambivalence towards anti-social behaviour. Rather our interviewees had weighed up the likely benefits and drawbacks involved and at times came to the conclusion they would be better off doing nothing, rather than risk the situation deteriorating further or "making things even worse". Those who had families were particularly concerned about the potential repercussions for their children if they reported incidents: "I needed to protect my family but I was worried about it escalating." Some residents also reported that these fears were justified by subsequent events, with one victim indicating that "the situation got worse when I reported it'. Residents making their own risk assessment of the likely outcome of making a complaint also used knowledge of what had happened to other neighbours or acquaintances who had reported anti-social behaviour and were less inclined to report incidents if their neighbour's situation had worsened as a result of a report.

\section{Fear of retaliation}

A fear of retaliation was prevalent amongst the residents who participated in our research, and this reduced residents' propensity either to enact informal social control by directly challenging alleged perpetrators or to make an official complaint. Our findings support those of the 2004/05 British Crime Survey in which a quarter of unreported incidences of noisy neighbours and drug dealing were explained by fear of reprisals (Upson, 2006). This fear was evident in the reluctance of most residents even to discuss the issue of drug dealing during our research. One resident acknowledged that whilst considering reporting an incident:

"I was a bit concerned that the men who went up there to smoke dope might retaliate if they realised their place was under threat"

Whilst official agencies understandably downplay the risk of reprisals, both our analysis of agency case files and the experiences of those victims and witnesses that we interviewed indicated that a small number of individuals who had reported an incident did experience harassment. This ranged from verbal warnings to vandalism and threats to themselves and their families. One resident said: "People are scared. 
p. 75. Active Citizenship in the Governance of Anti-social Behaviour in the UK: Exploring the Non-Reporting of Incidents

They're right to be fearful because families do retaliate. I've seen it happen before to other people who live near here."

Our findings suggest that agencies' strategies of reassurance that deny the risks involved in reporting are likely to be less effective than the provision of accurate information about the actual levels of retaliation and the mechanisms in place to protect complainants. Our research also identified some practical steps that local agencies could take to address the fear of retaliation. These include countering widespread 'urban myths' such as the common belief that perpetrators can access police radio frequencies to identify complainants and utilising more sensitive and innovative responses to complaints, such as interviewing victims or witnesses outside the immediate locality of their home. We were told of alleged examples of police officers turning up in marked cars to interview a complainant and then going directly and immediately to confront the alleged perpetrator. Taking these steps is crucial to the effectiveness of local anti-social behaviour strategies as our research consistently found a fault line between residents' willingness to make anonymous 'informal' complaints and their subsequent unwillingness to make formal statements or to act as witnesses.

\section{The importance of the actions of other neighbours}

Most of the policy and practice aimed at increasing reporting levels conceptualises victims and witnesses of anti-social behaviour as individuals or individual households. However, our research found that the behaviour of individuals was strongly influenced by the collective response to anti-social behaviour amongst their immediate neighbours. Analysis of case files frequently showed the difficulties local agencies had in sustaining the engagement of an individual complainant or witness when other residents refused to become involved. This often led to resentment and resignation amongst potential witnesses, and in some cases to their withdrawal from investigations. Conversely, where residents perceived that others were also willing to make a complaint this could lead to a re-affirming dynamic of group action. In the words of one resident: "We had had enough. Enough of us were willing to make a complaint."

The act of getting together with neighbours to bring a case was important not only for evidence-gathering reasons. It also signalled to the complainants that they had the much needed moral and emotional support of neighbours, and that this would increase the chances that their complaints case would be effective: "People are backing other people up in complaints. It makes the case a bit better."

\section{Cultures of non- engagement with agencies}

A further factor explaining the non-reporting of incidents was deep-rooted local cultures of 'minding your own business' and not getting involved with formal agencies in order to address neighbourhood problems. In some cases this was linked to a distrust of the police and others in authority, and an unwritten rule of non-co-operation with the police and 'not grassing' which extended to adults and young people alike and which resulted in either a toleration of quite serious anti-social behaviour or residents attempting to resolve problems themselves. Many longer-term residents reported to us that both anti-social behaviour and the non-reporting of incidents were the way things are around here'. More positively, some residents believed that their local knowledge and social connectivity to their neighbourhood would enable them to resolve anti-social behaviour informally. 
p. 76. Active Citizenship in the Governance of Anti-social Behaviour in the UK: Exploring the Non-Reporting of Incidents

\section{Taking alternative action}

Residents resolving problems themselves may be conceptualised as a positive explanation for the non-reporting of some incidents to official agencies. Over four ten (43-percent) of respondents in the 2004/05 British Crime Survey complained directly to noisy neighbours (Upson, 2006). This provides evidence of the enactment, if not efficacy, of the forms of active citizenship and communal mechanisms of informal social control which government discourse promotes. However, our research found that very few residents had attempted to negotiate or resolve an incident informally with a neighbour and the 2004/05 British Crime Survey found that only one in ten respondents complained directly to alleged perpetrators about types of anti-social behaviour other than noise. This suggests that the problems with engaging residents in formal social control processes are not explained by robust informal social control at the neighbourhood level. It should also be noted that our studies identified that not all alternative action is positive or appropriate. Rather, attempts by residents to "sort things out themselves' could result in violent verbal or physical responses to alleged perpetrators. At the extreme end of this spectrum of responses are co-ordinated vigilante actions and reprisals (see Girling et al., 1998; although no examples of this type of activity were discovered in the research studies informing this article).

\section{Discussion: the interface of officialdom and active citizenship}

Innes and Jones (2006) correctly identify the complexity of the relationship between formal and informal social control within anti-social behaviour strategies. Our research confirms the non-linear relationship between an official authority presence and enhanced informal behavioural regulation mechanisms amongst citizens, of which the non-reporting of incidents is emblematic. Our findings indicate the need for a more nuanced conceptualisation of non-reporting, both in disentangling its different causal factors and in recognising that a 'solution' to the problem is not achievable simply through refocused official intervention and greater 'support' to victims and witnesses.

Caution is also required in providing an over-simplified and limiting conceptualisation of what local residents desire from agency interventions. Whilst policy discourse suggests a need to be 'on the side of the law abiding majority' and that residents simply want the anti-social behaviour to cease, we found that neighbours experiencing anti-social behaviour recognised underlying causal factors, such as alcohol addiction or poor mental health, and therefore wanted perpetrators to be helped and supported in tandem with action to reduce the immediate presenting behavioural problems that they were victims of.

There is also a need to understand and address the differential willingness of residents to report incidents anonymously, which our research suggests may well be increasing, and the continuing reluctance of residents to become involved in more visible and sustained forms of active citizenship such as making formal statements, maintaining incident diaries or giving evidence in court. This also requires a focus on the collective dynamics of acts of citizenship rather than an individualistic focus on each witness or victim. In other words, the perceptions about the actual and likely behaviour of other neighbours influences individuals' propensity to report incidents and to engage in subsequent actions with official agencies. Although these agencies often provided intensive and effective support to witnesses, securing the active participation of fellow citizens is important and perhaps should be the subject of greater prioritisation within anti-social behaviour strategies. 
p. 77. Active Citizenship in the Governance of Anti-social Behaviour in the UK: Exploring the Non-Reporting of Incidents

Although policy discourse utilises the concept of collective efficacy to suggest a mutually reinforcing synergy between formal and informal social control, many practitioners articulated control processes as comprising 'zero sum' parallel mechanisms, along the lines of the former Deputy Prime Minister, who stated:

"This is about a new form of governance for people to play their part...not simply leaving it to the councillor and the council"

(John Prescott, quoted in Hetherington, 2005)

There was considerable concern amongst practitioners that new formal mechanisms such as CCTV, covert surveillance and the use of professional witnesses risked residents ceding their active role in neighbour dispute resolution and the enforcement of behavioural norms within local neighbourhoods. Whilst these formal techniques had been important in overcoming problems of non-reporting and particularly the gathering of evidence, there was also a view that their use could corrode communities' capacities for self-regulation. In a cyclical process, an overreliance on 'leaving things to the police or council' meant a lack of social presence or informal dialogue in public space, whereby social control is only enacted through anonymous reports to the police. This increased reactive presence ("flashing blue lights" as one practitioner described it) deepens a perception amongst residents of widespread serious anti-social behaviour in their neighbourhood in which their own direct response would be risky or inappropriate. Practitioners argued for a reaffirmation of the responsibilities of local residents to ensure that anti-social behaviour strategies did not reduce communities' capacities for informal social control and self-policing.

Our studies also found limited use of new and alternative channels for reporting incidents, including wardens, concierges and Neighbourhood Watch schemes, a finding borne out by the 2004/05 British Crime Survey (Upson, 2006). Despite attempts to provide new figures of authority and to expand the 'policing family' and to enhance the range of 'surrogate regulators' (Crawford, 2006) within neighbourhoods, the police and local authority remained the two agencies that most incidents were reported to. This may be a positive finding which reflects the fact that wardens and concierges are developing a different role within local communities. This differentiation between the police, Councils, wardens and concierges is important in facilitating engagement with different sections of local communities. However, other intermediary reporting and neighbour dispute resolution mechanisms are also essential but are presently underutilised in most local anti-social behaviour strategies. These include mediation (see Casey and Flint, 2006) and third-party reporting routes through trusted advocacy organisations for racially or religiously motivated or homophobic anti-social behaviour.

Finally, there is a problem with policy rationales that conceptualise both enhanced formal social control and reinvigorated informal social control being developed within a social vacuum. Rather, the cultural norms around 'not grassing' and the widespread fear of retaliation highlight the contested and competing regimes of power and legitimacy that operate within local communities (Stenson, 2005). Official authority is constantly struggling to demonstrate its sovereignty and dominance at the neighbourhood level, enacted through effective enforcement and the assurance of 'protection' to witnesses and victims. However, the strength, and historically embedded nature, of informal social processes suggest a limitation to the capacities of both agencies and citizens to 'win back' their communities. Most residents do not conceive of attempts to tackle anti-social behaviour in terms of re-enacting a previous civility and latent social control. Rather anti-social behaviour is regarded as a longstanding and normalised element of social life in their neighbourhood. Whilst official agencies may be able to address barriers to reporting arising from perceptions of their 
p. 78. Active Citizenship in the Governance of Anti-social Behaviour in the UK: Exploring the Non-Reporting of Incidents

ineffectiveness or poor support to victims and witnesses, addressing wider cultural regimes is a much more ambitious project. Given the social and psychological pressures facing residents, there is a need to recognise a difference between appropriate and realistic active citizenship and the almost heroic citizenship that may be necessary in 'taking a stand' against anti-social behaviour and the considerable personal costs involved in doing so.

\section{Conclusions}

These research findings suggest the need to re-conceptualise citizen empowerment and responsibility within anti-social behaviour strategies, based on the established recognition within civic and community participation fields that such empowerment is based on appropriate guidance, information, opportunity and capacity. This requires examining the social context within which residents are likely to report incidents to formal authority figures or utilise new anti-social behaviour hotline telephone numbers. Residents strongly desire some guidance about what constitutes anti-social behaviour and an appropriate complaint and therefore require some common framework, including a more explicit account of the need for some tolerance of diversity and differential lifestyles, particularly those of young people. This may result in a move away from the self-definition of harassment, alarm or distress inherent within the Crime and Disorder Act 1998 and Anti-social Behaviour Order applications. This need not be over-prescriptive or dismissive of the differential impact of anti-social behaviour amongst individuals, nor will it undermine the reflexivity and discretion of citizens. Rather, it empowers individuals to make a more informed decision about reporting an incident and reduces the likelihood of them perceiving that their complaint is not being taken seriously. It also requires a more comprehensive dialogue with residents about the realities of service provision and formal social control mechanisms (i.e. levels of policing, rationales for warden deployment patterns, realistic timescales for legal action, actual levels of harassment or retaliation following complaints). As part of this dialogue, a more explicit account of the difficulties that agencies have in pursuing action in the absence of resident involvement may be more effective than generalised appeals at the local level or the moral exhortation within national discourse. Acknowledging the difficulties and concerns that residents have about reporting incidents would also be useful, perhaps aligned with the greater use of anonymous 'testimonials' from residents who have reported incidents about the positive and negative aspects of their experience.

There is also a need to locate enhanced mechanisms for developing the interface between formal and informal social control with a wider politics of behaviour (Field, 2003) and a more comprehensive and politically-informed account of responsibility. King (2006) makes a series of important contributions to these issues. He identifies that conceptualisations of individual responsibility within policy processes should focus upon the instrumental, rather than moral element of responsibility. In other words individuals or groups should be given responsibility because they are actually able to address a social problem rather than because they ought to. King also makes the important point that responsibility-based policies, particularly related to anti-social behaviour, are targeted at the most disadvantaged and vulnerable populations and in the process, deflect a focus upon the responsibilities of wider society for tackling the causal reasons for anti-social behaviour being concentrated in deprived neighbourhoods. 
p. 79. Active Citizenship in the Governance of Anti-social Behaviour in the UK: Exploring the Non-Reporting of Incidents

\section{Acknowledgements}

We are very grateful to all of the research participants and for the support of the Glasgow Housing Association and the Scottish Executive. We also wish to acknowledge the significant contribution of Emma McCoulough and Emma Davidson, without whom this article would not have been possible. Thanks are also due to Kesia Reeve for her very insightful comments on an earlier version of this article.

* Correspondence Address: Rionach Casey and John Flint, Centre for Regional Economic and Social Research, Sheffield Hallam University, Unit 10, Science Park, Howard Street, S1 1WB, UK. Email: r.casey@shu.ac.uk and j.f.flint@shu.ac.uk.

\section{References}

Atkinson, R. and Flint, J. (2004) Order Born of Chaos? The Capacity for Informal Social Control in Disempowered and 'Disorganised' Neighbourhoods. Policy and Politics, 32, 3, 333-350.

Corbett, J. MacLeod, P. Martin, C. and Hope, S. (2005) Scotland's People: Results from the 2005 Scottish Household Survey. Edinburgh: Scottish Executive.

Crawford, A. (2006) Networked Governance and the Post-Regulatory State?: Steering, Rowing and Anchoring the Provision of Policing and Security. Theoretical Criminology, 10, 4, 449-479.

Casey, R. and Flint, J. (2006) Approaches to Neighbour Conflict Resolution: A Case Study of Mediation Sheffield. Sheffield: CRESR.

Etzioni, A. (1995) The Spirit of Community: Rights, Responsibilities and the Communitarian Agenda. London: Fontana Press.

Field, F. (2003) Neighbours from Hell: The Politics of Behaviour. London: Politico's.

Flint, J. (2006) Citizen Empowerment Strategies and Anti-social Behaviour Policy in the UK. Géographie, Economie and Société, 8, 1, 17-36.

Flint, J., Casey, R., Davidson, E., Pawson, H. and McCoulough, E. (2007a) Tackling antisocial behaviour in Glasgow: An evaluation of policy and practice in the Glasgow Housing Association. Glasgow: Glasgow Housing Association.

Flint, J., Green, S., Hunter, C., Nixon, J., Parr, S., Manning, J., Wilson, I., Pawson, H., Davidson, E. and Sanderson, D. (2007b) Evaluation of the Implementation and Impact of Local Anti-social Behaviour Strategies at the Neighbourhood Level. Edinburgh: Scottish Executive.

Girling, E., Loader, I. and Sparks, R. (1998) A Telling Tale: A Case of Vigilantism and its Aftermath in an English Town. British Journal of Sociology, 49, 3, 474-490.

Hetherington, P. (2005) Prescott's super parish revolution. The Guardian, 5 January 2005.

Home Office (2003) Respect and Responsibility- Taking a Stand Against Anti-social Behaviour. London: Home Office.

Innes, M. and Jones, V. (2006) Neighbourhood security and urban change: Risk, resilience and recovery. York: Joseph Rowntree Foundation.

King, P. (2006) What do we mean by responsibility? The case of UK housing benefit reform. Journal of Housing and the Built Environment, 21, 111-125.

McVie, S., Campbell, S. and Lebov, K. (2003) Scottish Crime Survey. Edinburgh: Scottish Executive.

Respect Task Force (2006) Respect Action Plan. London: Respect Task Force

Scottish Executive (2003) Putting our communities first: a strategy for tackling antisocial behaviour. Edinburgh: Scottish Executive. 
p. 80. Active Citizenship in the Governance of Anti-social Behaviour in the UK: Exploring the Non-Reporting of Incidents

Stenson, K. (2005) Sovereignty, biopolitics and the local government of crime in Britain. Theoretical Criminology, 9, 3, 265-287.

Upson, A. (2006) Perceptions and experience of anti-social behaviour: Findings from the 2004/05 British Crime Survey. London: Home Office. 